\title{
Abuso sexual infantil: impacto no comportamento da criança e perspectivas para a
} Terapia Ocupacional

\section{Child sexual abuse: impact on child behavior and perspectives for Occupational Therapy}

\section{Abuso sexual infantil: impacto en el comportamiento del niño y perspectivas para la Terapia Ocupacional}

\author{
Recebido: $22 / 12 / 2020$ \\ Aprovado: 05/07/2021 \\ Publicado: 26/08/2021
}

\section{Giovana Rodrigues dos Santos ${ }^{1}$ \\ Aline Sarturi Ponte ${ }^{2}$ Tânia Fernandes Silva ${ }^{3}$}

Esta é uma revisão integrativa, realizada em 2019, através do Portal Regional da Biblioteca Virtual em Saúde, em português, considerando o período de 2009 a 2019, com o objetivo de conhecer a produção científica sobre o impacto do abuso sexual na infância e apontar as possibilidades de ação da Terapia Ocupacional. Considerou-se os descritores e suas combinações: "Abuso sexual infantil"; "Abuso sexual infantil AND comportamento"; "Violência sexual criança e adolescente"; "Abuso sexual infantil AND comportamento"; "Violência sexual infantil atenção primaria em saúde"; "Violência sexual infantil saúde pública/Violência sexual infantil saúde coletiva"; "Abuso sexual infância AND terapia ocupacional/Violência sexual infantil Terapia Ocupacional". Do levantamento inicial de 238 artigos, foram elegíveis seis artigos, e construídas duas categorias temáticas: Abuso Sexual Infantil: uma realidade perversa; e Abuso Sexual Infantil: consequências e reflexões da Terapia Ocupacional. Observou-se que a maior ocorrência de abuso sexual foi no ambiente intrafamiliar, com o pai, padrasto e irmão da vítima como os principais abusadores. 0 abuso causa possíveis traumas psicossociais que interferem diretamente na vida da criança, e gera consequência no desenvolvimento e no comportamento destas. A intervenção terapêutica ocupacional poderá prevenir consequências psíquicas, sociais e emocionais que acometem as crianças vítimas de abuso sexual.

Descritores: Abuso sexual na infância; Adaptação psicológica; Terapia Ocupacional.

This is an integrative review carried out in 2019, through the Portal Regional da Biblioteca Virtual em Saúde, in Portuguese, between 2009 and 2019. It aimed to know the scientific production on the impact of sexual abuse in children and point out the possibilities of Occupational Therapy action. The following descriptors and their combinations were considered: "Abuso sexual" infantil (Child "sexual abuse"); "Abuso sexual" infantil AND comportamento (Child "sexual abuse" AND behavior); "Violência sexual" infantil saúde pública/ "Violência sexual infantil" saúde coletiva (Child "Sexual violence" public health/"Child secuaç violence" collective health); Abuso sexual infantil AND comportamento (Child sexual abuse AND behavior); "Violência sexual" infantil atenção primaria em saúde (Child "sexual violence" primary health care); "Violência sexual" infantil saúde pública/"Violência sexual infantil" saúde coletiva ("Child sexual violence" public health/"Child sexual violence" collective health); "Abuso sexual" infância AND terapia ocupacional/"violência sexual" infantil Terapia Ocupacional (Child "Sexual abuse" AND occupational therapy/"sexual violence" childhood Occupational Therapy). From an initial survey of 238 articles, six articles were eligible and two thematic categories were constructed: Child Sexual Abuse: a perverse reality; and Child Sexual Abuse: consequences and reflections of Occupational Therapy. It was observed that the highest occurrence of sexual abuse occurs in the intra-family environment, with the victim's father, stepfather and brother as the main abusers. Abuse causes possible psychosocial traumas that directly interfere in the child's life, generating consequences in their development and behavior. Occupational therapeutic intervention can prevent psychological, social and emotional consequences that affect children who are victims of sexual abuse.

Descriptors: Child abuse, Sexual; Adaptation, Psychological; Occupational Therapy.

Esta es una revisión integradora realizada en 2019, a través del Portal Regional de la Biblioteca Virtual en Salud, en portugués, considerando el período de 2009 a 2019, con el objetivo de conocer la producción científica sobre el impacto del abuso sexual en la infancia y señalar las posibilidades de actuación de la Terapia Ocupacional. Se consideraron los descriptores y sus combinaciones: "Abuso sexual infantil"; "Abuso sexual infantil AND comportamento" ("Abuso sexual infantil AND comportamiento"); "Violência sexual criança e adolescente" ("Violencia sexual niños y adolescentes"); "Abuso sexual infantil AND comportamento" ("Abuso sexual infantil AND comportamiento"); "Violência sexual infantil atenção primaria em saúde" ("Violencia sexual infantil atención primaria de salud"); "Violência sexual infantil saúde pública/Violência sexual infantil saúde coletiva" ("Violencia sexual infantil salud pública/Violencia sexual infantil salud colectiva"); "Abuso sexual infância AND terapia ocupacional/Violência sexual infantil Terapia Ocupacional" ("Abuso sexual infancia AND terapia ocupacional/Abuso sexual infantil Terapia Ocupacional"). A partir de la encuesta inicial de 238 artículos, seis artículos fueron elegibles y, dos categorías temáticas se construyeron: Abuso Sexual Infantil: una realidad perversa; y, Abuso Sexual Infantil: consecuencias y reflexiones de la Terapia Ocupacional. Se observó que la mayoría de los abusos sexuales se producen en el entorno intrafamiliar, siendo el padre, el padrastro y el hermano de la víctima los principales abusadores. El abuso provoca posibles traumas psicosociales que interfieren directamente en la vida del niño y genera consecuencias en su desarrollo y comportamiento. La intervención terapéutica ocupacional puede prevenir las consecuencias psíquicas, sociales y emocionales que afectan a los niños víctimas de abuso sexual.

Descriptores: Abuso sexual infantil; Adaptación psicológica; Terapia Ocupacional.

1. Acadêmica do Curso de Terapia Ocupacional da Universidade Federal de Santa Maria (UFSM), Santa Maria, RS, Brasil. ORCID: 0000-0003-3955-7984 E-mail: giovanarsantos17@gmail.com

2. Terapeuta Ocupacional. Especialista em Reabilitação Físico Motora. Mestre e Doutora em Distúrbios da Comunicação Humana. Santa Maria, RS, Brasil. ORCID: 0000-0003-4775-3467. E-mail: alinesarturi@hotmail.com

3. Terapeuta Ocupacional. Especialista em Psicopedagogia. Mestre em Comunicação Socvial. Doutora em Saúde Coletiva. Professora Adjunta e coordenadora do Curso de Terapia Ocupacional da UFSM, Santa Maria, RS, Brasil. ORCID: 0000-0002-9741-313X E-mail: drataniaf@yahoo.com.br 


\section{INTRODUÇÃO}

A

o considerar as fases do desenvolvimento infantil, torna-se extremamente importante acompanhar o desenvolvimento humano, pois este é um processo único, contínuo e de mudança. 0 período pré-natal e os anos iniciais são decisivos na evolução da criança, por serem advindos da experiência oferecida pelo meio ambiente e da interação com as características biopsicossocial herdadas geneticamente ${ }^{1}$.

0 termo abuso sexual deve ser compreendido como um ato em que um indivíduo é submetido por outro para obter gratificação sexual contra sua vontade. 0 ato do abuso sexual vai além do desrespeito ao outro, pois envolve uma relação de poder e busca dos excessos ${ }^{2}$.

O Abuso Sexual Infantil (ASI) é considerado um dos maiores problemas de saúde pública, que ocorrem em todo o mundo, em todas classes sociais, faixas etárias e sem distinção de gênero. No ASI, a criança é induzida pelo seu abusador a cometer atos sexuais contra sua vontade ${ }^{3}$.

O ASI caracteriza-se como qualquer ato praticado pela pessoa que usa a criança ou adolescente para satisfazer seus desejos sexuais, sendo relação sexual, jogo ou qualquer ato de natureza erótica ${ }^{4}$. Além disto, fatores como: a exploração sexual, tal como o incentivo, a prostituição, a escravidão sexual, a pornografia infantil e o turismo sexual, também são considerados ASI.

Na perspectiva do desenvolvimento da criança, quando esta vivencia um trauma como a violência sexual, tal fato pode acarretar grandes malefícios ao seu desenvolvimento, e causar comprometimentos emocionais, comportamentais e sociais. Entende-se que a criança, muitas vezes, não compreende o que está acontecendo ou não sabe lidar com esta violência, sendo estas práticas impostas pela força física, ameaças ou indução da sua vontade pelo abusador. Em muitos casos, o abuso sexual ocorre dentro da própria família, causando um dano ainda maior, por existir o vínculo afetivo entre a vítima e o abusador, causando, desta forma, a quebra do vínculo familiar e da confiança da criança em seus pais ${ }^{5}$.

0 abuso sexual pode gerar consequências variadas, como pode-se observar pelos indicadores comportamentais: perda de apetite, rejeição do pai ou da mãe, mudanças bruscas, manifestações de resistência ao se despir, dificuldades para sentar e manterem relações sociais, problemas escolares, fantasias e comportamentos regressivos, evitar o contato físico ou apresentar comportamentos sedutores, além de conhecimentos precoces e inadequados para a idade da criança sobre sexualidade ${ }^{2}$.

A atuação da Terapia Ocupacional com crianças vítimas de violência sexual é de grande importância, pois este profissional tem o papel de facilitador do restabelecimento do vínculo familia, e resoluções dos conflitos advindos do trauma. As intervenções deste profissional estarão voltadas para o reestabelecimento das condições físicas, psicológicas e sociais da criança e do adolescente 6 .

O terapeuta ocupacional lançará mão de atividades que minimizem os impactos e as consequências da violência, através do uso de recursos terapêuticos, como o uso do Modelo Lúdico. $\mathrm{O}$ ato de brincar pode ser um importante recurso utilizado para a compreensão do mundo que cerca a criança e do que advém com ela, possibilitando a solução de conflitos e frustrações, promovendo assim um processo de autoconhecimento, relação ao outro além de explorar e desenvolver capacidades e habilidades da criança ${ }^{6}$.

O terapeuta ocupacional se coloca como um facilitador de expressões e da reelaboração do processo vivido pela criança, de modo que ela possa se reconhecer como um ser atuante no mundo, através do modelo lúdico, proporcionado pelo ato do brincar ${ }^{7}$.

0 ASI pode provocar graves traumas psicopatológicos, como comportamentos sexualizados e inadequados para a idade da criança, depressão, choro fácil, medo das pessoas em geral, fraco desempenho escolar, pensamento suicida ${ }^{8}$. Desta forma, este estudo teve por objetivo conhecer a produção científica sobre o impacto do abuso sexual na infância e apontar as possibilidades de ação da Terapia Ocupacional. 


\section{MÉTODO}

Trata-se de uma revisão integrativa, definida como uma ampla abordagem metodológica referente às revisões, que permitem a inclusão de estudos experimentais e não experimentais, para um melhor entendimento dos fenômenos analisados, além de combinar dados da literatura teórica e empírica, incorpora uma gama de propósitos: definição de conceitos, revisão de teorias e evidências, e análise de problemas metodológicos de um tópico particular 9 .

Para a construção deste estudo, foram respeitados os seguintes passos: 1) Identificação do tema e delimitação da questão da pesquisa; 2) Definição dos critérios de inclusão e exclusão, e de amostragem e busca na literatura; 3) Categorização dos estudos encontrados; 4) Avaliação dos estudos encontrados; 5) Análise dos resultados encontrados; e 6) Síntese do conhecimento.

A coleta de dados foi realizada no mês de novembro de 2019. A coleta foi realizada a partir de um levantamento bibliográfico de artigos científicos em revistas indexadas nas bases de dados da Biblioteca Virtual em Saúde (BVS). Foram consultadas as publicações de autores de referência na área, uma posterior leitura crítica e minuciosa de artigos no portal da BVS, utilizando os seguintes Descritores em Ciências da Saúde (DeCS): "Abuso sexual infantil"; "Abuso sexual infantil AND comportamento"; "Violência sexual criança e adolescente"; "Abuso sexual infantil AND comportamento"; "Violência sexual infantil atenção primaria em saúde"; "Violência sexual infantil saúde pública/Violência sexual infantil saúde coletiva"; "Abuso sexual" infância AND terapia ocupacional/Violência sexual infantil Terapia Ocupacional".

Como critérios de inclusão, consideraram-se os seguintes itens: 1) artigos indexados na BVS; 2) publicados nos últimos 10 anos (2009 a 2019); 3) disponíveis na íntegra; 4) com idioma em português e; 5) com os assuntos principais: abuso sexual infantil; abuso sexual infantil e Terapia Ocupacional e violência sexual infantil.

Para os critérios de exclusão, consideraram-se os seguintes itens: 1) obras publicadas em formato de teses, dissertações, livros, capítulos de livros ou resenhas; 2) artigos publicados em idiomas que não português; 3) artigos duplicados na base de dados; e 4) artigos que não estavam de acordo com a temática sobre abuso sexual infantil, retirando os tinham como foco principal, sobre violência e negligência.

Os estudos selecionados para compor esta revisão bibliográfica integrativa foram dispostos em uma planilha do Microsoft Excel ${ }^{\circledR} 2010$ e categorizados de acordo com os autores/ano de publicação, periódico, tipo do estudo, título do artigo, objetivo do estudo e resultado principal encontrado.

\section{RESULTADOS}

Foram identificados 238 artigos sobre o tema abuso sexual infantil, que, após análise baseada no objetivo traçado, nos critérios de inclusão e exclusão e nos descritores de busca: "Abuso sexual infantil AND comportamento", com seis artigos; quatro para "Violência sexual infantil saúde pública/Violência sexual infantil" saúde coletiva"; um para "Violência sexual infantil atenção primaria em saúde"; e dois sobre "Abuso sexual infância AND terapia ocupacional/violência sexual infantil terapia ocupacional", resultando inicialmente em 13 estudos elegíveis. A Figura 1 aponta o ciclo de busca dos artigos, bem como o quantitativo de artigos encontrados, nas bases de dados, de acordo com os descritores. 
Figura 1. Ciclo de busca com a correlação do quantitativo dos artigos encontrados nas bases. Rio Grande do Sul, Santa Maria, 2019.

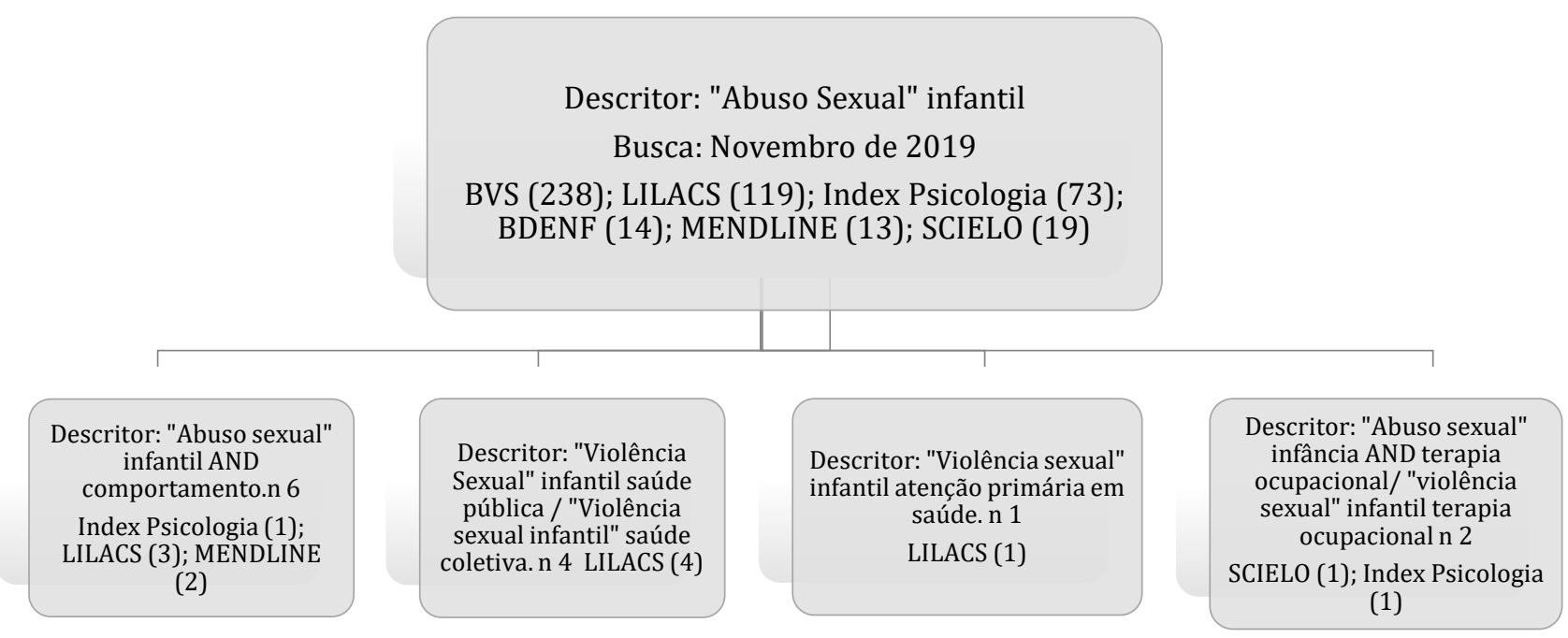

O processo de seleção dos artigos resultou num total de 238 estudos. Destes, 181 foram excluídos pela leitura do título, quatro por serem duplicatas, resultando na identificação de 57 artigos. Destes, 40 foram excluídos considerando os critérios de exclusão, resultando em 10 artigos selecionados para leitura na íntegra e, destes, quatro foram excluídos por não terem como foco a temática prevista, pois discorriam sobre negligência e violência. Com esta exclusão, restaram seis artigos que se adequavam ao objetivo e proposta deste estudo (Figura 2). 
Figura 2. Fluxograma de coleta de artigos que compuseram os resultados. Rio Grande do Sul, Santa Maria, 2019.

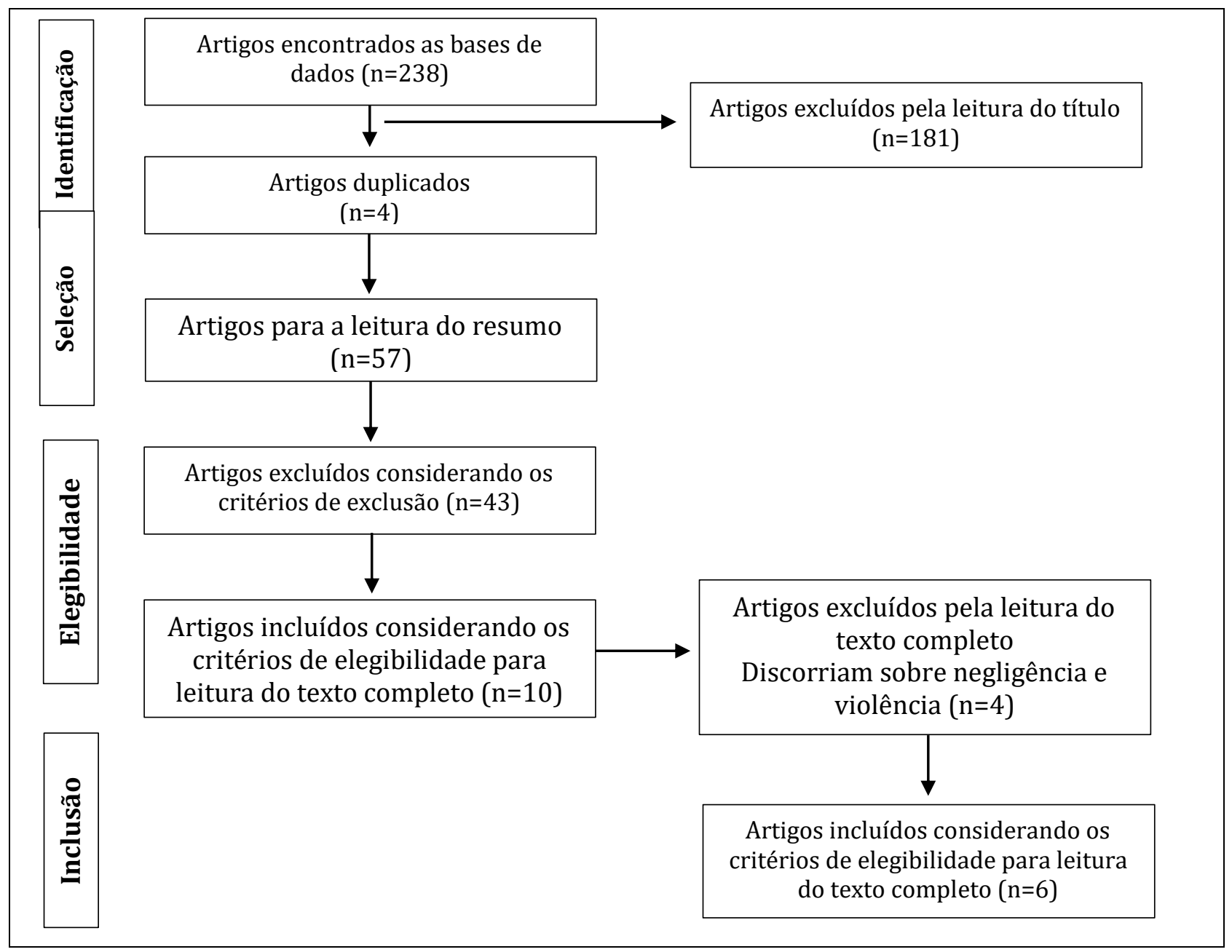

No Quadro 1, apresenta-se uma síntese das principais características dos seis artigos selecionados. Este apresenta dados de cada estudo, a partir das variáveis: autores/ano de publicação, periódico, tipo de estudo, título do artigo e objetivo do estudo.

Após a análise dos seis artigos selecionados, observou-se que as principais vítimas de ASI são meninas, crianças ou adolescente, cor parda ou negra (Artigos 1, 2, 3 e 5), baixa renda (Artigos 1 e 3) e que residem em regiões periféricas (Artigos 3 e 5). Os estudos apontaram que, na maioria das vezes, o ASI ocorre no ambiente intrafamiliar (Artigos 1, 3 e 5), sendo o agressor do sexo masculino (pai, padrasto, irmão), mas está violência também pode acontecer no ambiente extrafamiliar, podendo ser o agressor um desconhecido ou uma pessoa próxima da família (vizinho, namorado) (Artigo 5).

0 Artigo 2 faz uma reflexão sobre o ASI e a gravidez. Este estudo apontou que a maioria das meninas de até 13 anos que tiveram filhos foram negras. 0 estudo apontou a ocorrência de violência de repetição na maioria dos casos. Em relação ao acompanhamento pré-natal, observou-se o início tardio e um baixo número de consultas; e quanto ao tipo de parto, notouse maiores percentuais de cesárea. Com relação aos bebês, o estudo destacou que estes tiveram peso ao nascer e APGAR do $1^{\circ}$ minuto piores que das mães sem notificação de estupro. 
Quadro 1. Síntese dos estudos analisados na íntegra. Rio Grande do Sul, Santa Maria, 2019.

\begin{tabular}{|c|c|c|c|c|c|}
\hline № & $\begin{array}{c}\text { Autor/ } \\
\text { Ano }\end{array}$ & Periódico & $\begin{array}{l}\text { Tipo de } \\
\text { estudo }\end{array}$ & Título do artigo & Objetivo do estudo \\
\hline 1 & $\begin{array}{l}\text { Guimarãe } \\
\text { s, J.A.T.L; } \\
\text { Villela, } \\
\text { W.V; } \\
2011 .\end{array}$ & $\begin{array}{l}\text { Cadernos } \\
\text { Saúde } \\
\text { Publica }\end{array}$ & Descritivo & $\begin{array}{l}\text { Características da } \\
\text { violência física e sexual } \\
\text { contra crianças e } \\
\text { adolescentes atendidos } \\
\text { no IML de } \\
\text { Maceió, Alagoas, Brasil }\end{array}$ & $\begin{array}{l}\text { Descrever as características da } \\
\text { violência contra crianças e } \\
\text { adolescentes atendidos no } \\
\text { Instituto Médico-Legal de Maceió } \\
\text { (IML/Maceió), Alagoas, Brasil }\end{array}$ \\
\hline 2 & $\begin{array}{l}\text { Souto, } \\
\text { R.M.C.V; } \\
\text { et al; } \\
2017\end{array}$ & $\begin{array}{l}\text { Ciência \& } \\
\text { Saúde } \\
\text { Coletiva }\end{array}$ & Descritivo & $\begin{array}{l}\text { Estupro e gravidez de } \\
\text { meninas de até } 13 \text { anos } \\
\text { no } \\
\text { características } \\
\text { implicações na saúde } \\
\text { gestacional, parto e } \\
\text { nascimento. }\end{array}$ & $\begin{array}{l}\text { Descrever as características de } \\
\text { mães com até } 13 \text { anos e analisar o } \\
\text { perfil dos casos de estupro } \\
\text { notificado nessa mesma faixa } \\
\text { etária e as repercussões dessa } \\
\text { violência durante } \\
\text { gravidez e parto. }\end{array}$ \\
\hline 3 & $\begin{array}{l}\text { Honorato, } \\
\text { L.G.F; et } \\
\text { al.; } 2018\end{array}$ & $\begin{array}{l}\text { Arquivos } \\
\text { Brasileiro } \\
\text { s de } \\
\text { Psicologia }\end{array}$ & $\begin{array}{l}\text { Descritivo, } \\
\text { exploratório, } \\
\text { quantitativo }\end{array}$ & $\begin{array}{l}\text { Violência na Infância e } \\
\text { Adolescência: Perfil } \\
\text { notificado } \\
\text { na mesorregião do } \\
\text { Baixo Amazonas. }\end{array}$ & $\begin{array}{l}\text { Traçar um perfil da violência } \\
\text { infantil notificada na região oeste } \\
\text { do Estado do Pará, com ênfase na } \\
\text { violência física e sexual. }\end{array}$ \\
\hline 4 & $\begin{array}{l}\text { Nascimen } \\
\text { to, A.F; } \\
\text { Deslandes } \\
2016 \text { S,F.; }\end{array}$ & $\begin{array}{l}\text { Revista de } \\
\text { Saúde } \\
\text { Coletiva }\end{array}$ & Bibliográfico & $\begin{array}{l}\text { A construção da agenda } \\
\text { pública brasileira de } \\
\text { enfrentamento } \\
\text { violência } \\
\text { infanto-juvenil }\end{array}$ & $\begin{array}{l}\text { Analisar a } \text { emergência } \\
\text { da questão social da violência } \\
\text { sexual infanto-juvenil como } \\
\text { problema público, sua inclusão e } \\
\text { permanência na agenda formal } \\
\text { das políticas nacionais nas } \\
\text { décadas } \\
\text { de } 1990 \text { e } 2000 .\end{array}$ \\
\hline 5 & $\begin{array}{l}\text { Santana, } \\
\text { J.S.S.; } \\
\text { Santana, } \\
\text { S.P; } \\
\text { Lopes, } \\
\text { M.L.; } \\
\text { 2011. } \\
\end{array}$ & $\begin{array}{l}\text { Revista } \\
\text { Baiana } \\
\text { de Saúde } \\
\text { Pública }\end{array}$ & $\begin{array}{l}\text { Quantitativo, } \\
\text { descritivo e } \\
\text { transversal }\end{array}$ & $\begin{array}{l}\text { Violência sexual contra } \\
\text { crianças e adolescentes: } \\
\text { análise de notificações } \\
\text { dos conselhos tutelares } \\
\text { e departamento de } \\
\text { polícia } \\
\text { técnica }\end{array}$ & $\begin{array}{l}\text { Apresentar características de } \\
\text { casos registrados de violência } \\
\text { sexual contra crianças e } \\
\text { adolescentes no município de } \\
\text { Feira de Santana, Bahia, no } \\
\text { período de } 2002 \text { a } 2006 \text {. }\end{array}$ \\
\hline 6 & $\begin{array}{l}\text { Pimentel, } \\
\text { A.S.G; } \\
\text { Araújo, } \\
\text { L.S.; } 2009 .\end{array}$ & $\begin{array}{l}\text { Psicologia } \\
\text { em Estudo }\end{array}$ & $\begin{array}{l}\text { Qualitativa de } \\
\text { orientação } \\
\text { fenomenológi } \\
\text { co-existencial } \\
\text { gestáltica }\end{array}$ & 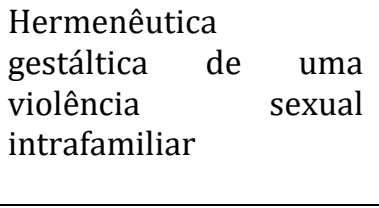 & $\begin{array}{l}\text { Desvelar alguns significados } \\
\text { atribuídos à violência sexual } \\
\text { intrafamiliar. }\end{array}$ \\
\hline
\end{tabular}

O Artigo 4 apresenta uma contextualização do amplo movimento de articulação e mobilização social ocorrido na década de 1990 que direcionou a construção do Plano Nacional de Enfrentamento da Violência Sexual Infanto-juvenil como política pública intersetorial, sendo aprovado na década de 2000 por 160 organizações participantes do Encontro Nacional, na cidade de Natal - RN "Carta de Natal” e ratificado na Assembleia Ordinária do Conselho Nacional dos Direitos da Criança e do Adolescente (CONANDA).

No Artigo 6, realizou-se uma análise considerando a teoria da interpretação de Ricoeur, conceitos da Gestalt-Terapia que pondera o contato, figura-fundo e nutrição psicológica e da Terapia Ocupacional que baseia suas reflexões nas áreas, componentes e contextos de desempenho. Assim, foi possível compreender a vivencia da adolescente, considerando o seu campo existencial, observou-se que o ASI interferiu na sua autoimagem e autoestima, desencadeando um conjunto de demandas no campo psíquico, ocupacional e afetivo e relacional. 


\section{DISCUSSÃO}

Os estudos da presente revisão foram agrupados em duas categorias, a saber: Abuso Sexual Infantil: uma realidade perversa; e Abuso Sexual Infantil: consequências e reflexões da Terapia Ocupacional.

\section{Abuso Sexual Infantil: uma realidade perversa}

0 abuso sexual é a violência mais perversa praticada contra crianças e adolescentes, pois atinge o corpo, a mente e a dignidade das vítimas ${ }^{9-11}$. Os estudos analisados demonstram que 0 ASI atinge mais comumente crianças e adolescentes do gênero feminino (Artigo 1, 2, 3 e 5), corroborando dados de outras pesquisas ${ }^{12-14}$.

Em relação a cor, a maioria dos estudos analisados apontou crianças e adolescente de cor parda ou negra (Artigo 1, 2, 3 e 5), de acordo com estudos sobre a temática 10,13,14. Assim, acredita-se que o fato da maioria das notificações corresponderem às vítimas do sexo feminino pode ser, em parte, pela falta de notificação por parte das pessoas do gênero masculino, sendo motivado pelo medo de passar constrangimentos decorrentes do preconceito que gira em torno da identidade sexual e pela repercussão familiar e social ${ }^{10,13-16}$.

Nos estudos analisados, as crianças e adolescentes eram de famílias de baixa renda (Artigos 1 e 3), dados que corrobora os resultados de outras investigações sobre a temática1719. Mas é importante salientar que a situação de baixa renda, em si, não justifica qualquer prática de violência contra crianças, adolescentes ou quaisquer outras pessoas, pois a violência faz parte do cotidiano de todas as classes sociais ${ }^{20}$.

Em relação a residência, observou-se que a maioria das crianças e adolescentes que sofrem ASI residem em bairros periféricos (Artigos 3 e 5), característica apontada em um estudo que aborda o assunto ${ }^{20}$. O ASI acontece em todas as classes sociais, o fato da maior frequência nas classes sociais menos favorecidas pode estar relacionado às formas de procurar ajuda e dar encaminhamento ao problema. Pois as famílias de classes sociais mais elevadas buscam essa ajuda no setor privado (consultórios particulares), assim facilitando a manutenção do sigilo da situação. No caso das famílias de classes sociais mais baixas, a procura ocorre em serviços do setor público ${ }^{20}$. Ressalta-se que os serviços públicos também garantem o sigilo das vítimas e o acesso aos dados é realizado respeitando a legislação nacional vigente.

A partir da análise dos estudos selecionados, pode-se perceber o aumento do índice de abusos sexuais contra a criança e adolescente no ambiente intrafamiliar (Artigos 1, 3 e 5). Sendo um ato praticado por algum membro da família ou pessoa responsável pela mesma, os estudos demonstram que, muitas vezes, o ASI é cometido pelo pai, padrasto ou irmão da vítima, a casa em que a criança reside é o principal local dos abusos ${ }^{12-14}$.

$\mathrm{O}$ abuso sexual, quando vivenciado pela criança ou adolescente no contexto familiar, pode acarretar grandes complicações, intensificando o trauma causado pela aproximação afetiva entre o abusador e a vítima ${ }^{5}$. Assim, aponta-se ser de extrema importância o suporte à família, à criança e ao adolescente que foram violentados, pois é nesta fase do desenvolvimento que ocorrem acentuadas transformações, que vão desde físicas a neurológicas, cognitivas e comportamentais.

Quando uma criança não recebe o suporte necessário, podem ocorrer graves declínios no seu desenvolvimento, necessitando assim de uma pessoa que exerça o papel de cuidador, que proporcione um ambiente saudável, garantindo um desenvolvimento psicossocial adequado, pois se entende que é dever do Estado e da família proteger e assegurar os direitos estabelecidos pelo Estatuto da Criança e do Adolescente (ECA) ${ }^{21}$, lei 8.069, de 13 de julho 1990, que dispõem sobre a proteção integral da criança e adolescente. Portanto, é por meio deste suporte que os efeitos negativos de tal violência possam suavizar tais efeitos ${ }^{10,22}$.

Um ponto importante referido no Artigo 2 foi a gravidez, as reflexões realizadas neste estudo corroboram outros estudos que tratam da temática12,23,24. 0 crescente aumento da representatividade de crianças e adolescentes gravidas é um fenômeno expressivo no Brasil ${ }^{25-}$ 
27 e no mundo ${ }^{28}$. A iniciação sexual precoce pode gerar riscos ao desenvolvimento biológico, psicológico e social ${ }^{25-27}$. Um fator que corrobora este dado é a ausência de estudos e políticas junto a este público ${ }^{28}$, sendo assim, torna-se importante conhecer as necessidade e demandas destas crianças e adolescentes e, assim, traçar estratégias de ação para diminuição dos casos de gravidez.

O Artigo 4 aponta que, atualmente, há um crescimento das notificações de violência sexual em decorrência da implementação de políticas públicas e divulgação da ferramenta eletrônica como o "Disque 100", dando maior visibilidade para as situações de abuso sexual de forma geral e, consequentemente, aumentando o número destes tipos de notificações ${ }^{12}$. Mas a não notificação dos abusos ainda é uma realidade. Este fator foi apresentado nos estudos analisados, relacionando-se à dificuldade em comprovar tal ato, pois nem sempre é possível encontrar sinais de violência através de exame médico legal, além do sentimento de culpa por parte da vítima ${ }^{10,13,15}$.

0 aumento do número de notificações demonstra a fragilidade da rede em prover cuidados de saúde e de proteção, sendo de extrema importância a promoção da saúde e de políticas públicas que proporcionem uma estrutura social para o desenvolvimento individual da criança e adolescente e de sua família, destacando a importância de implantação de um trabalho multidisciplinar voltado para ações integradas de cuidado e atenção à saúde e a vida, que busquem promover estratégias mais estruturadas, garanta a atenção integral, e a garantida de informações e o esclarecimento sobre a importância de se interromper o ciclo de violência e preservar vidas ${ }^{11,12,29}$.

Para um melhor funcionamento das redes de apoio e cuidado, necessita-se que a equipe que acolha os casos de crianças e adolescentes violentados, devendo estar preparados tecnicamente, emocionalmente e psicologicamente para que os atendimentos, sejam eficazes, ressaltando a importância e necessidade da implantação de cursos de capacitação/ sensibilização de profissionais com abordagem nas áreas de Educação, Justiça e Saúde para informá-los sobre a imensa e invisível problemática da violência sexual na vida das vítimas ${ }^{30,31}$.

\section{Abuso Sexual Infantil: consequências e reflexões da Terapia Ocupacional}

A violência sexual infantil é um fenômeno que ultrapassa fronteiras, sendo algo que acontece em todos os países. Devido a sua frequência e, muitas vezes, não receber a atenção devida, o que pode causar grandes sequelas, desencadeando um conjunto de demandas no desenvolvimento biológico, social ${ }^{25-27}$, no campo psíquico ${ }^{16,25-27,29,32}$, emocional, ocupacional, comportamental, afetivo e relacional ${ }^{16,29,32}$. Estas sequelas são referidas pelos autores dos seis artigos analisados neste estudo.

No campo psíquico e emocional, a violência poderá provocar o uso abusivo de álcool e outras drogas, depressão, ansiedade, tendência suicida, comprometendo a autoimagem e a autoestima, o aparecimento de comportamento sexualizado, distúrbios do sono, sintomas psicóticos, quadros de ansiedade, expressões repetidas através de gestos, sentimento de rejeição, confusão, humilhação, vergonha e medo ${ }^{16,29,30}$.

Em relação aos comprometimentos de cunho comportamental apresentados nos estudos analisados, ressaltam-se alterações na alimentação, na aprendizagem, aumento incomum na frequência do banho ${ }^{29}$. No campo relacional, têm-se dificuldades em criar novos vínculos sociais e afetivos, provocando o isolamento, as dificuldades de socialização 12,16,29,30. A criança ou adolescente que sofreu abuso pode apresentar comportamentos de promiscuidade, disfunções sexuais, coitofobia, disfunções menstruais, imagem corporal pobre, sexualização ou abuso de seus filhos, comportamento auto e heterodestrutivo, baixa autoestima, culpa, sentimentos de vergonha e traição, distúrbios psiquiátricos e homossexualidade ${ }^{2,29}$.

A atuação do profissional de Terapia Ocupacional frente a estas vítimas (referida no Artigo 6) conjectura-se a partir da compreensão dos significados que as crianças ou adolescentes atribuem à ocorrência do abuso sexual, bem como o entendimento das experiências vivenciadas pelas vítimas no seu campo existencial, que se reflete na sua forma de 
ser-no-mundo e nas interações que estabelece consigo e com seus familiares e amigos ${ }^{16,33}$. Resignificando estes valores e a vida destas crianças e adolescentes, nota-se que o profissional não somente interfere no cotidiano da criança, mas também promove o amparo da família, o que irá favorecer os resultados de sua intervenção terapêutica, principalmente quando existe uma estimulação mais cotidiana no ambiente onde a criança se sente acolhida².

Diante de indivíduos que sofreram abuso sexual, o terapeuta ocupacional procura recuperar a dimensão ativa da existência humana, que é fruto de um novo olhar, utilizando como instrumento de atuação o uso da atividade diversas, por meio do ato de fazer e da postura do ser. Assim, o profissional lançará mão do trabalho com atividades expressivas e criativas, associadas a abordagens psicodinâmicas e sociais, tomando como base toda e qualquer expressão humana verbal e não verbal para fins terapêuticos. Mais do que as palavras, as atividades exprimem os pensamentos e sentimentos destas crianças e adolescentes ${ }^{2,33}$.

As abordagens terapêuticas poderão evitar um declínio no quadro de desenvolvimento psíquico, social e emocional das crianças que sofreram violência sexual, possibilitando também a identificação precoce das alterações de comportamento advindas de tal ato, pois o abuso sexual também pode causar a perda da subjetividade, ter consequências físicas que poderão afetar diretamente no desenvolvimento da criança, durantes as fases do seu desenvolvimento, causando prejuízos ao longo da vida ${ }^{2,33}$.

Uma abordagem terapêutica precoce poderá prevenir comportamentos inadequados, como tentativa de suicídio, uso abusivo de álcool e outras drogas, minimizando episódios traumáticos, o desenvolvimento de transtornos mentais e possibilitando que esta criança se reconheça como um ser atuante e não perder a sua subjetividade ${ }^{2}$.

\section{CONCLUSÃO}

A partir dos estudos analisados, pode-se observar que um crescimento do ASI no ambiente intrafamiliar, sendo este ato cometido pelo pai, padrasto ou irmão da vítima. As crianças e adolescentes mais acometidos pelo abuso sexual são do gênero feminino, de cor/raça parda.

O ASI gera muitos impactos negativos na vida das crianças e adolescentes. Estes enfrentam as consequências psicológicas, emocionais, físicas e sociais desta violência ao longo de suas vidas. Torna-se importante à criação de estratégias de promoção, educação e prevenção por meio de abordagem em equipe multidisciplinar para minimizar os agravos no desenvolvimento das vítimas.

Outro ponto mencionado nas publicações é o envolvimento da família e da sociedade em geral para a detecção dos sintomas e a busca de ajuda qualificada para estas crianças e adolescentes, evitando assim, possíveis traumas.

Ao considerar a abordagem em equipe multiprofissional, que incluirá profissionais das áreas da saúde, humanas e da assistência social, torna-se importante discutir o papel do Terapeuta Ocupacional na intervenção junto às crianças e aos adolescentes que sofreram ASI. Isto pois este profissional realiza as suas intervenções baseadas nas necessidades dos indivíduos, utiliza-se de atividades lúdicas para traçar estratégias para minimizar os impactos do abuso sexual no desenvolvimento infantil, os traumas, promover qualidade de vida e ressignificar os sentidos e a vida destas crianças e adolescentes e, assim, permitir que as crianças e os adolescentes se expressem e criem, tomando um lugar do ser, ser um sujeito e ter seu lugar no mundo.

Este estudo sugere uma reflexão acerca da temática numa perspectiva das equipes de saúde, principalmente no que se refere à atenção primária, pela qual equipes das Unidades Básicas de Saúde possam perceber e observar os principais sinais de alerta para casos de ASI.

Como limitações desse estudo, ressalta-se a escassez de pesquisas científicas que discutam o impacto do ASI no comportamento de criança e adolescentes, a intervenção de Terapeutas Ocupacionais junto a sob a perspectiva da saúde coletiva. 


\section{REFERÊNCIAS}

1. Souza JM, Verissimo MLOR. Desenvolvimento infantil: análise de um novo conceito. Rev Latinoam Enferm. [Internet]. 2015 [citado em 11 nov 2019]; 23(6):1097-104. Disponível em: http://www.scielo.br/scielo.php?pid=S0104-

$11692015000601097 \&$ script=sci_arttext\&tlng=pt

2. Machado TFA. Criança vítima de pedofilia: fatores de risco e danos sofridos [Internet]. [dissertação]. São Paulo: Faculdade de Direito da Universidade de São Paulo; 2013 [citado em 01 jul 2021]. 166p. Disponível em: https://www.teses.usp.br/teses/disponiveis/2/2136/tde13022014-111701/publico/Dissertacao_Mestrado_Talita_Ferreira_Alves_Machado.pdf

3. Eastman AC. Relatório mundial sobre a violência e a saúde da OMS: uma resposta ao desafio da violência. Rev Saúde [Internet]. 2002 [citado em 11 out 2019]; 3(3):1-12. Disponível em: http://portaldeboaspraticas.iff.fiocruz.br/wp-content/uploads/2019/04/14142032relatorio-mundial-sobre-violencia-e-saude.pdf

4. Florentino BRB. As possíveis consequências do abuso sexual praticado contra crianças e adolescentes. Fractal [Internet]. 2015 [citado em 12 nov 2019]; 27(2):139-44. Disponível em: http://www.scielo.br/pdf/fractal/v27n2/1984-0292-fractal-27-2-0139.pdf

5. Lima IVB, Diolina J. Consequências psicológicas do abuso sexual na infância e adolescência: uma ferida invisível. AJES [Internet]. 2013 [citado em 01 jul 2021]; Disponível em: http://www.site.ajes.edu.br/direito/arquivos/20131030201243.pdf

6. Rezende EA. Consequências da violência na infância ao longo da vida: uma revisão narrativa. [monografia]. Brasília, DF: Universidade de Brasília; 2016. 36p.

7. Santos, RCF. Violência sexual e a formação de educadores: uma proposta de intervenção [Internet]. [dissertação]. Presidente Prudente, SP: Faculdade de Ciências e Tecnologia; 2011 [citado em 01 jul 2021]. 147p. Disponível em: https://repositorio.unesp.br/handle/11449/92264

8. Krug EG, Dahlberg LL, Mercy JA, Zwi AB, Lozano R, editors. World report on violence and health [Internet]. Geneva: World Health Organization; 2002 [citado em 01 jul 2021]. Disponível em: https://apps.who.int/iris/bitstream/handle/10665/42495/9241545615_eng.pdf

9. Souza MT, Silva MD, Carvalho R. Revisão integrativa: o que é e como fazer. Einstein [Internet]. 2010 [citado em 07 set 2019]; 8(1):102-6. DOI: https://doi.org/10.1590/s167945082010rw1134

10. Santana JSS, Santana SP, Lopes ML. Violência sexual contra crianças e adolescentes: análise de notificações dos conselhos tutelares e departamento de polícia técnica. Rev Baiana Saúde Pública [Internet]. 2011 [citado em 09 set 2019]; 35(Supl1):68-86. Disponível em: http://files.bvs.br/upload/S/0100-0233/2011/v35nSupl1/a2299.pdf

11. Piana MC, Bezerra MS. Marcas na infância: o poder do adulto sobre a criança e a violência sexual. Libertas [Internet]. 2019 [citado em 09 out 2019]; 19(1):200-2. Disponível em: https://periodicos.ufjf.br/index.php/libertas/article/view/27782

12. Souto RMCV, Porto DL, Pinto IV, Vidotti CCF, Barufaldi LA, Freitas MG, et al. Estupro e gravidez de meninas de até 13 anos no Brasil: características e implicações na saúde gestacional, parto e nascimento. Ciênc Saúde Colet. [Internet]. 2017 [citado em 10 out 2019]; 22(9): 2909-18. Disponível em: http://www.scielo.br/scielo.php?script=sci_abstract\&pid=S1413-

81232017002902909\&lng=en\&nrm=iso\&tlng=pt

13. Guimarães JATL, Villela WV. Características da violência física e sexual contra crianças e adolescentes atendidos no IML de Maceió. Cad Saúde Pública [Internet]. 2011 [citado em 10 out 2019]; 27(8):1647-53. Disponível em: http://www.scielo.br/scielo.php?pid=S0102311X2011000800019\&script=sci_abstract\&tlng=pt

14. Honorato LGF, Souza AC, Santos TSR, Lopes OG, Zukowsky-Tavares C. Violência na infância e adolescência: perfil notificado na mesorregião do Baixo Amazonas. Arq Bras Psicol. [Internet]. 2018 [citado em 10 out 2019]; 
$70(2): 266-84$.

Disponível

em:

http://pepsic.bvsalud.org/scielo.php?script=sci_abstract\&pid=S1809-

$52672018000200019 \& \operatorname{lng}=$ pt\&nrm=iso

15. Platt VB, Back IC, Hauschild DB, Guedert, J. Violência sexual contra crianças: autores, vítimas e consequências. Ciênc Saúde Colet. [Internet]. 2018 [citado em 09 nov 2019]; 23(4):1019-31. Disponível em: http://www.scielo.br/scielo.php?script=sci_arttext\&pid=S141381232018000401019

16. Vertamatti MAF. Fatores associados a duração e severidade do abuso sexual infantil em São Paulo - Brasil [Internet]. [tese]. São Paulo: Universidade de São Paulo; 2017 [citado em 01 jul 2021]. 423p. Disponível em: https://teses.usp.br/teses/disponiveis/6/6136/tde-15012018133051/pt-br.php

17. Fontes LFC, Conceição OC, Machado S. Violência sexual na adolescência, perfil da vítima e impactos sobre a saúde mental. Ciênc Saúde Colet. [Internet]. 2017 [citado em 10 fev 2021]; 22(9):2919-28. Disponível em: https://www.scielosp.org/article/csc/2017.v22n9/29192928/pt/

18. Talon MSV. Perfil epidemiológico dos menores vítimas de violência sexual em Cuiabá e região. Cad Univag [Internet]. 2018 [citado em 10 fev 2021]; 9(1):46-52. Disponível em: http://www.periodicos.univag.com.br/index.php/caderno/article/viewFile/1211/1388

19. Nunes ACP, Silva CC, Carvalho CTC, Silva FG, Fonseca PCSB. Violência infantil no Brasil e suas consequências psicológicas: uma revisão sistemática. Braz J Dev. [Internet]. 2020 [citado em 10 fev 2021]; 6(10):79408-41. Disponível https://www.brazilianjournals.com/index.php/BRJD/article/view/18453/14870

20. Roque EMST, Ferriani MGC. Desvendando a violência doméstica contra crianças e adolescentes sob a ótica dos operadores do direito na Comarca de Jardinópolis - SP. Rev Latinoam Enferm. [Internet]. 2002 [citado em 10 fev 2021]; 10(3):334-44. Disponível em: https://www.scielo.br/scielo.php?script=sci_arttext\&pid=S0104-11692002000300008

21. Presidência da República (Brasil). Lei no 8.069, de 13 de julho de 1990. Estatuto da Criança e do Adolescente [Internet]. Brasília, DF, 13 jul 1990 [citado em 03 dez 2019]. Disponível em: http://www.planalto.gov.br/ccivil_03/leis/18069.htm

22. Nascimento AF, Deslandes SF. A construção da agenda pública brasileira de enfrentamento da violência sexual infanto-juvenil. Physis [Internet]. 2016 [citado em 09 nov 2019]; 26(4):1171-91. Disponível em: http://www.scielo.br/scielo.php?pid=S0103$73312016000401171 \&$ script $=$ sci_abstract $\&$ tlng $=p t$

23. Silva AJC, Trindade RFC, Oliveira LLF. Presunção do abuso sexual em crianças e adolescentes: vulnerabilidade da gravidez antes dos 14 anos. Rev Bras Enferm. [Internet]. 2020 [citado em 10 fev 2021]; 73(Supl4):e20190143. Disponível em: https://www.scielo.br/j/reben/a/Kzh6wbDhSVZhDFvqMspCDMB/?format=pdf\&lang=pt

24. Lordello SEM, Costa LF. Violência sexual intrafamiliar e gravidez na adolescência: uma leitura bioecológica. Psicol Teor Pesqui. [Internet]. 2020 36(esp):1-11. Disponível em: http://www.scielo.br/scielo.php?script=sci_arttext\&pid=S0102-

37722020000300216\&lng=en\&nrm=iso

25. Farias R, Moré COO. Impact of pregnancy on at-risk, 10-14 year-old adolescents. Psicol Reflex Crit [Internet]. 2012 [citado em 10 fev 2021]; 25(3):596-604. Disponível em: https://www.researchgate.net/publication/262657001_Impact_of_Pregnancy_on_at-Risk_1014_Year-Old_Adolescents

26. World Health Organization. Health for the world's adolescents: a second chance in the second decade [Internet]. Geneva: World Health Organization; 2014 [citado em 10 fev 2021]. Disponível decade/en/ em: https://www.who.int/maternal_child_adolescent/documents/second-

27. Santos MJ, Mascarenhas MDM, Rodrigues MTP, Monteiro RA. Caracterização da violência sexual contra crianças e adolescentes na escola - Brasil, 2010-2014. Epidemiol Serv Saúde 
[Internet]. 2018 [citado em 01 jul 2021]; 27(2):e2017059. Disponível em: https://www.scielo.br/scielo.php?script=sci_arttext\&pid=S2237-96222018000200305

28. Miura PO, Tardivo LSLPC, Barrientos DMS, Egry EY, Macedo CM. Adolescência, gravidez e violência doméstica: condições sociais e projetos de vida. Rev Bras Enferm. [Internet]. 2020 [citado em 10 fev 2021]. 73(Supl1):e20190111. Disponível em: https://www.scielo.br/j/reben/a/kpSZMqX43mdS3rsWNg6Qpyf/?format=pdf\&lang=pt

29. Pimentel ASG, Araújo LS. Hermenéutica gestáltica de una violéncia sexual intrafamiliar. Psicol Estud. [Internet]. 2009 [citado em 11 out 2019]; 14(4):659-67. Disponível em: http://www.scielo.br/scielo.php?pid=S1413-

$73722009000400006 \&$ script=sci_abstract\&tlng=pt

30. Neves AS, Castro GB, Hayeck CM, Cury DG. Abuso sexual contra a criança e o adolescente: reflexões interdisciplinares. Temas Psicol. [Internet]. 2010 [citado em 11 out 2019]; 18(1):99111. Disponível em: http://pepsic.bvsalud.org/scielo.php?script=sci_arttext\&pid=S1413389X2010000100009

31. Reymao AEN, Gomes AJP. A violência contra a criança e o adolescente no arquipélago do Marajó (PA) e seu direito ao reconhecimento como sujeito de direito e de ser protegida e resguardada. Rev Dir Soc, Seg Previd Soc. [Internet]. 2019 [citado em 09 out 2019]; 5(2):84104. Disponível em: https://indexlaw.org/index.php/revistadssps/article/view/6038

32. Tavares C. Adultos sem juízo, crianças em prejuízo [Internet]. [dissertação]. Porto, Portugal: Universidade do Porto; 2013 [citado em 01 jul 2021]. 104p. Disponível em: https://repositorioaberto.up.pt/bitstream/10216/67923/2/30335.pdf

33. Cabral TG. Abuso sexual na infância, reflexões sobre a abordagem da terapia ocupacional nos contextos culturais. In: III Congresso de Educação em Saúde da Amazônia (COESA); 2014; Belém. Belém: Universidade Federal Pará; 2014. p. 12-4.

Editora Associada: Fernanda Carolina Camargo

\section{CONTRIBUIÇÕES}

Giovana Rodrigues dos Santos contribuiu na concepção, coleta e análise dos dados e redação. Aline Sarturi Ponte participou da redação e revisão. Tânia Fernandes Silva atuou na concepção do estudo e revisão.

\section{Como citar este artigo (Vancouver)}

Santos GR, Ponte AS, Silva TF. Abuso sexual infantil: impacto no comportamento da criança sob a perspectiva da saúde coletiva. REFACS [Internet]. 2021 [citado em inserir dia, mês e ano de acesso]; 9(Supl. 2):820-831. Disponível em: inserir link de acesso. DOI: inserir link do DOI

\section{Como citar este artigo (ABNT)}

SANTOS, G. R.; PONTE, A. S.; SILVA, T. F. Abuso sexual infantil: impacto no comportamento da criança sob a perspectiva da saúde coletiva. REFACS, Uberaba, MG, v. 9, Supl. 2, p. 820-831, 2021. DOI: inserir link do DOI. Disponível em: inserir link de acesso. Acesso em: inserir dia, mês e ano de acesso.

\section{Como citar este artigo (APA)}

Santos, G.R., Ponte, A.S., \& Silva, T.F. (2021). Abuso sexual infantil: impacto no comportamento da criança sob a perspectiva da saúde coletiva. REFACS, 9(Supl. 2), 820-831. Recuperado em inserir dia, mês e ano de acesso de inserir link de acesso. DOI: inserir link do DOI. 